Am J Nephrol 2008;28:304-310

DOI: $\underline{10.1159 / 000111386}$
Received: April 26, 2007

Accepted: September 18, 2007

Published online: November 16, 2007

\title{
Renal Function and Cardiovascular Response to Mental Stress
}

\author{
Stephen L. Seliger ${ }^{a}$ Leslie I. Katzel ${ }^{a}$ Jeffrey C. Fink ${ }^{a}$ Matthew R. Weir ${ }^{b}$ \\ Shari R. Waldstein ${ }^{c}$ \\ a University of Maryland School of Medicine, Maryland VA Healthcare System, ${ }^{b}$ Division of Nephrology, \\ University of Maryland School of Medicine, and 'Department of Psychology, University of Maryland, \\ Baltimore County, Baltimore, Md., USA
}

\section{Key Words}

Renal function - Cardiovascular reactivity · Blood pressure

\begin{abstract}
Background/Aims: Cardiovascular reactivity (CVR), defined as an exaggerated hemodynamic response to mental stress, is a putative vascular risk factor and may reflect sympathetic hyperactivity. Chronic kidney disease (CKD) is also associated with sympathetic hyperactivity and vascular risk, but its relationship with CVR is unknown. Methods: CVR was assessed in 107 individuals without overt cardiovascular disease or diabetes. Blood pressure and heart rate responses were elicited by three experimental tasks designed to evoke mental stress. Glomerular filtration rate (eGFR) was estimated using the MDRD formula. General linear models estimated the association between renal function and CVR, adjusting for potential confounders. Results: Mean age was 66 years and $11 \%$ had eGFR of $<60 \mathrm{ml} / \mathrm{min} / 1.73 \mathrm{~m}^{2}$. After multivariate adjustment, a low eGFR was associated with a greater stress response of systolic blood pressure, heart rate, and pulse pressure. Associations were only partially attenuated after adjustment for lipids and glucose tolerance. When considered as a continuous variable, lower eGFR was associated with a greater blood pressure response after adjustment for glycemia. Conclusion: Although there were relatively few participants with CKD, these results suggest a relationship
\end{abstract}

between CKD and greater CVR. Further investigation is warranted into factors that mediate this relationship and potential clinical consequences of this exaggerated response to stress in CKD.

Copyright $\odot 2007$ S. Karger AG, Basel

\section{Introduction}

Cardiovascular reactivity (CVR), defined as an exaggerated hemodynamic response to mental stress, has been identified as a putative risk factor for hypertension [1], and coronary artery and cerebrovascular disease [25]. A tendency towards sympathetic hyperreactivity has been postulated to underlie this hyper-responsiveness to mental stress. Individuals who exhibit exaggerated responses to experimentally induced stress are believed to experience regular periodic increases in blood pressure in the setting of daily life stressors [6,7], which over time may contribute to vascular injury and morbidity.

Chronic kidney disease (CKD) is a highly prevalent condition which has also been associated with both sympathetic hyperreactivity $[8,9]$ and a higher risk of cardiovascular and cerebrovascular disease [10-12]. Although greater cardiovascular stress reactivity among individuals with CKD is plausible, no prior study has examined this association. It is possible that enhanced CVR may, in

\begin{tabular}{ll}
\hline KARGER & ( 2007 S. Karger AG, Basel \\
Fax +41613061234 & \\
$\begin{array}{l}\text { E-Mail karger@karger.ch } \\
\text { www.karger.com }\end{array}$ & $\begin{array}{l}\text { Accessible online at: } \\
\text { www.karger.com/ajn }\end{array}$
\end{tabular}

Stephen L. Seliger, MD, MS

Baltimore VA Med Center, Room 5D-151

Baltimore, MD 21201 (USA)

Tel. +1 410605 7000, ext. 5231, Fax +1 4106057849

E-Mail sseliger@medicine.umaryland.edu 
part, contribute to the excess cardiovascular morbidity and mortality noted in the presence of CKD. Accordingly, we examined the relation between renal function and cardiovascular stress reactivity among a sample of community-dwelling middle-aged and older adults free of clinically apparent cardiac disease and stroke. We hypothesized that individuals with impaired kidney function would exhibit a greater cardiovascular response to experimentally induced mental stress.

\section{Subjects and Methods}

\section{Study Population}

Eligible subjects included community-dwelling middle-aged and older adults (age $>55$ years) who were participants in an ongoing study of the inter-relations among cardiovascular risk factors, psychophysiological factors, neuro-imaging, and neurocognitive function $[5,13]$. Exclusion criteria were: history or clinical evidence of cardiac or peripheral vascular disease, prior stroke, diabetes, dementia (defined by a Mini-Mental State Exam (MMSE) score of $<24$ ), heavy alcohol consumption (>14 drinks/week), major hepatic or pulmonary disease, moderate-severe renal impairment (defined as serum creatinine $>2.0 \mathrm{mg} / \mathrm{dl}$ ), primary psychiatric disorder, neurological disease, and medications affecting central nervous system function (e.g., benzodiazepines, neuroleptics). None of the subjects were on lipid-lowering medications. Participants with mild-moderate hypertension were eligible but had their anti-hypertensive therapy withdrawn 2 weeks prior to mental stress testing (see below). Data are reported on 107 consecutive subjects. All participants gave informed consent, and all research was approved by the Institutional Review Boards of the University of Maryland, Baltimore, and the University of Maryland, Baltimore County.

\section{Experimental Protocol}

Participants received an initial medical evaluation including physical examination, blood chemistries, oral glucose tolerance test, and exercise treadmill test. All laboratory measurements were performed after an overnight fast. Serum creatinine was measured using an enzymatic method (Vitros 950, Ortho Clinical Diagnostics). Estimated glomerular filtration rate (eGFR) was computed using the abbreviated formula of Levey et al. [14]. Impaired glucose tolerance was defined according to American Diabetes Association criteria [15]. On a separate day from the initial examination, participants completed a psychophysiological assessment of cardiovascular responses to experimental mental stressors. Individuals taking antihypertensive medications were withdrawn from these drugs for 2 weeks before this visit, under medical supervision; the purpose of this medication withdrawal was to obtain stress reactivity measures uninfluenced by pharmacological agents. No specific instructions were given to participants regarding refraining from smoking. Participants performed a series of three 3-min experimental tasks in fixed order, as described previously [5]. These three tasks were selected to evoke negative emotions. (1) Anger recall involved a detailed description of a personally relevant anger-provoking incident chosen by the participant $[16,17]$. (2) In the speech/role play task [17], subjects participated in a hypothetical interpersonal scenario in which a close relative was being mistreated by the night staff of his/her nursing home, and in which the participants delivered a spontaneous speech to a confederate responsible nursing home administrator. Speech delivery was interrupted frequently with challenging statements, resulting in a provoking role-played interchange. (3) The mental arithmetic task involved serial subtractions by 7 (or 3 depending on performance) from 3-digit numbers. Participants responded aloud while being prompted to work faster, try harder, and make fewer mistakes.

A 10 -min rest period preceded each task; the last $4.5 \mathrm{~min}$ of this period were used as a 'baseline' period for data collection for each task. Supine blood pressure and heart rate were measured oscillometrically every $90 \mathrm{~s}$ during rest periods and every $60 \mathrm{~s}$ during the task period with an automated vital signs monitor (Dinamap Model 1846SX). Pulse pressure was calculated as the difference between each systolic (SBP) and diastolic blood pressure (DBP) measurement. Mean resting and task levels SBP, DBP, pulse pressure, and heart rate were computed from the 3 readings obtained during each respective baseline and task period.

\section{Statistical Analysis}

Renal function was dichotomized as impaired or non-impaired based on an eGFR threshold of $60 \mathrm{ml} / \mathrm{min} / 1.73 \mathrm{~m}^{2}$, according to the National Kidney Foundation Chronic Kidney Disease classification guidelines [18]; a secondary analysis considered eGFR as a continuous variable. Characteristics of participants with and without impaired renal function were compared using the $\chi^{2}$ test for categorical covariates and either the $t$ test or Wilcoxon rank sum test for continuous variables. The association between renal function and cardiovascular responses to mental stress, adjusted for potential confounders, was estimated using general linear models (GLM). The mean task-specific blood pressure or heart rate was entered as the dependent variable, with resting (pre-task) blood pressure/heart rate, the type of experimental task, and eGFR category entered as independent covariates. An identity link function and a Gaussian distribution of the dependent variable were specified, and robust (Huber/White sandwich) variance estimators were used to estimate standard errors of the regression coefficient, with clustering on each individual participant. Adjustment was made initially for a set of theoretically plausible confounders, based on a literature review of factors likely to influence renal function and CVR: age, gender, race, body mass index $\left(\mathrm{kg} / \mathrm{m}^{2}\right)$, hypertension, and aspirin use. Measures of glucose tolerance (fasting glucose and glucose $120 \mathrm{~min}$ following an oral glucose load) and lipids (triglycerides, HDL-cholesterol, and LDL-cholesterol) were included as additional covariates in exploratory models - although they have been shown to associate with renal function, the causal direction of this association is unclear, and therefore their roles as potential confounders versus mediators are uncertain.

Interactions between eGFR and the specific laboratory task were estimated by testing appropriate task-eGFR interaction terms - since no significant interaction was found ( $p \geq 0.3$ ), reactivity measures were collapsed across the three tasks using the GLM models. Prior work has suggested that collapsing reactivity measures across tasks improves the reliability of these measures [19]. All statistical analyses were performed using Intercooled Stata v8.2 (Statacorp, College Station, Tex., USA). 
Table 1. Characteristics of study population by estimated GFR (eGFR)

\begin{tabular}{|c|c|c|c|}
\hline Characteristic & $\begin{array}{l}\text { eGFR }<60 \mathrm{ml} / \mathrm{min} / \\
1.73 \mathrm{~m}^{2}(\mathrm{n}=12)\end{array}$ & $\begin{array}{l}\text { GFR } \geq 60 \mathrm{ml} / \mathrm{min} / \\
1.73 \mathrm{~m}^{2}(\mathrm{n}=95)\end{array}$ & $\mathrm{p}$ value \\
\hline Age, years & $70.7 \pm 4.7$ & $66.1 \pm 6.7$ & 0.01 \\
\hline Male, $\mathrm{n}$ & $9(75 \%)$ & $58(61 \%)$ & 0.5 \\
\hline Caucasian, $\mathrm{n}$ & $11(92 \%)$ & $85(89.5 \%)$ & 0.5 \\
\hline Hypertension, & $5(42 \%)$ & $25(26.6 \%)$ & 0.3 \\
\hline Antihypertensive medication use $^{1}, \mathrm{n}$ & $3(25 \%)$ & $13(14 \%)$ & 0.4 \\
\hline ACEI or ARB, $n$ & 2 & 2 & \\
\hline$\beta$-Blocker, $n$ & 1 & 6 & \\
\hline Diuretic, $\mathrm{n}$ & 0 & 3 & \\
\hline Ca-channel blocker, $\mathrm{n}$ & 0 & 3 & \\
\hline$\alpha$-Blocker, n & 0 & 6 & \\
\hline $\mathrm{BMI}, \mathrm{kg} / \mathrm{m}^{2}$ & $27.9 \pm 2.9$ & $27.3 \pm 5.0$ & 0.8 \\
\hline Mean resting $\mathrm{SBP}, \mathrm{mm} \mathrm{Hg}$ & $144.3 \pm 25.9$ & $129.4 \pm 18.2$ & 0.01 \\
\hline Mean resting DBP, $\mathrm{mm} \mathrm{Hg}$ & $69.7 \pm 11.0$ & $69.4 \pm 9.5$ & 0.9 \\
\hline Mean resting heart rate, beats/min & $61.6 \pm 9.1$ & $61.8 \pm 9.2$ & 0.9 \\
\hline Current/former smoker, $\mathrm{n}$ & $7(58 \%)$ & $48(51 \%)$ & 0.8 \\
\hline $\mathrm{Hb}, \mathrm{g} / \mathrm{dl}$ & $14.1 \pm 1.2$ & $14.2 \pm 1.3$ & 0.7 \\
\hline Fasting glucose, $\mathrm{mg} / \mathrm{dl}$ & $104.3 \pm 23.2$ & $94.1 \pm 10.5$ & 0.048 \\
\hline 2-hour glucose, mg/dl & $167.9 \pm 77.7$ & $129.5 \pm 43.2$ & 0.07 \\
\hline Impaired fasting glucose $\mathrm{e}^{2}, \mathrm{n}$ & $6(50 \%)$ & $20(22 \%)$ & 0.07 \\
\hline Impaired glucose tolerance ${ }^{3}, \mathrm{n}$ & $8(67 \%)$ & $32(34 \%)$ & 0.05 \\
\hline LDL-C, mg/dl & $123.4 \pm 26.1$ & $121.1 \pm 25.0$ & 0.5 \\
\hline TGL, mg/dl & $144[106,155]$ & $98[75,119]$ & 0.008 \\
\hline HDL-C, mg/dl & $41[38,48]$ & $50[41,63]$ & 0.05 \\
\hline Albumin, g/dl & $4.35 \pm 0.34$ & $4.35 \pm 0.26$ & 0.9 \\
\hline Aspirin use, $\mathrm{n}$ & $1(8.3 \%)$ & $18(19.0 \%)$ & 0.5 \\
\hline \multicolumn{2}{|c|}{$\begin{array}{l}\text { Values are given as means } \pm \mathrm{SD} \text {, number of subjects with per- } \\
\text { centages in parentheses, or medians with the interquartile ranges } \\
\text { in brackets. } \\
\text { ACEI = Angiotensin-converting enzyme inhibitor; } \mathrm{ARB}=\text { an- } \\
\text { giotensin receptor blocker; } \mathrm{SBP}=\text { systolic blood pressure; } \mathrm{DBP}= \\
\text { diastolic blood pressure; } \mathrm{Hb}=\text { hemoglobin; } \mathrm{LDL}-\mathrm{C}=\text { low-density } \\
\text { lipoprotein cholesterol; HDL-C = high-density lipoprotein cho- } \\
\text { lesterol; TGL = triglyceride. To convert glucose to millimoles per }\end{array}$} & \multicolumn{2}{|c|}{$\begin{array}{l}\text { liter, multiply by } 0.05551 \text {; to convert LDL-C to millimoles per liter, } \\
\text { multiply by } 0.02586 \text {; to convert triglyceride to millimoles per liter, } \\
\text { multiply by } 0.01129 \text {; to convert HDL-C to millimoles per liter, } \\
\text { multiply by } 0.02586 \text {. } \\
{ }^{1} \text { At time of enrolment; all participants on antihypertensive } \\
\text { medications received stress reactivity testing after a } 2 \text {-week wash- } \\
\text { out period without such medications. }{ }^{2} \text { Fasting glucose } \geq 100 \mathrm{mg} / \\
\mathrm{dl} .{ }^{3} \text { Glucose at } 120 \text { min following oral load } \geq 140 \mathrm{mg} / \mathrm{dl} \text {. }\end{array}$} \\
\hline
\end{tabular}

\section{Results}

\section{Study Population}

The median serum creatinine was $0.9 \mathrm{mg} / \mathrm{dl}$, mean eGFR was $79.2 \mathrm{ml} / \mathrm{min} / 1.73 \mathrm{~m}^{2}(\mathrm{SD}=18.9)$, and $11 \%(\mathrm{n}=$ 12) had an eGFR of $<60$ (range $48-59 \mathrm{ml} / \mathrm{min} / 1.73 \mathrm{~m}^{2}$. Participants with an eGFR of $<60 \mathrm{ml} / \mathrm{min} / 1.73 \mathrm{~m}^{2}$ were significantly older and had higher resting clinic systolic and diastolic blood pressure, higher fasting serum glucose, and were more likely to have impaired glucose tolerance (table 1). In addition, average triglyceride levels were higher and HDL-cholesterol levels lower among those with an eGFR of $<60 \mathrm{ml} / \mathrm{min} / 1.73 \mathrm{~m}^{2}$.

\section{Stress Reactivity and eGFR}

Age-adjusted stress responses of SBP and DBP, heart rate, and pulse pressure were on average greater among those with an eGFR of $<60 \mathrm{ml} / \mathrm{min} / 1.73 \mathrm{~m}^{2}$, with significant differences detected for SBP, pulse pressure, and heart rate for the anger recall task (fig. 1). In multivariate regression (GLM) models, those with a low eGFR had significantly greater increases in SBP, pulse pressure, and heart rate compared to those with an eGFR of $\geq 60 \mathrm{ml} /$ $\min / 1.73 \mathrm{~m}^{2}$, even after adjustment for age, gender, race, body mass index, history of hypertension, and use of aspirin (table 2; model 1). Additional adjustment for fasting glucose and serum glucose following an oral glucose load 

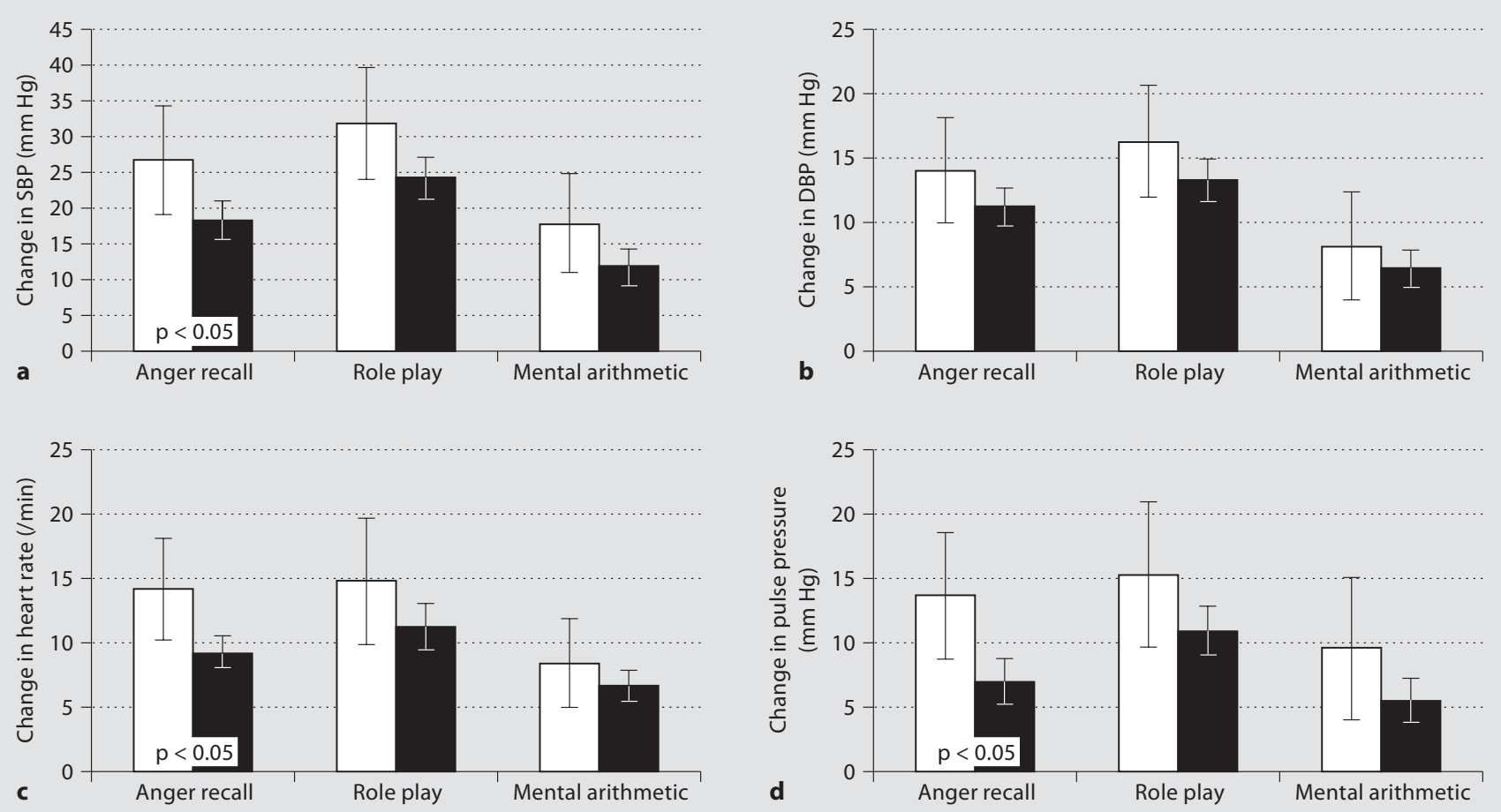

Fig. 1. Age-adjusted cardiovascular reactivity by the estimated glomerular filtration rate (eGFR) and experimental task. Error bars indicate $95 \%$ confidence intervals. $\square=$ eGFR $<60 \mathrm{ml} / \mathrm{min}$; $\mathbf{\square}=\mathrm{eGFR} \geq 60 \mathrm{ml} / \mathrm{min}$. a Change in systolic blood pressure (SBP). b Change in diastolic blood pressure (DBP). c Change in heart rate. d Change in pulse pressure.

Table 2. Association between stress reactivity measures and eGFR $<60 \mathrm{ml} / \mathrm{min} / 1.73 \mathrm{~m}^{2}$

\begin{tabular}{|c|c|c|c|c|c|}
\hline Hemodynamic measure & Unadjusted & Model 1 & Model 2 & Model 3 & $\begin{array}{l}\text { Test for task-eGFR } \\
\text { interaction }\end{array}$ \\
\hline$\Delta \mathrm{SBP}$ & $\begin{array}{l}8.5(2.4,14.6) \\
p=0.005\end{array}$ & $\begin{array}{l}7.8(2.0,13.6) \\
p=0.009\end{array}$ & $\begin{array}{l}8.0(2.3,13.6) \\
p=0.007\end{array}$ & $\begin{array}{l}7.0(0.6,13.4) \\
p=0.03\end{array}$ & 0.6 \\
\hline$\Delta \mathrm{DBP}$ & $\begin{array}{l}3.3(-0.8,7.5) \\
\mathrm{p}=0.12\end{array}$ & $\begin{array}{l}2.2(-1.5,5.9) \\
\mathrm{p}=0.2\end{array}$ & $\begin{array}{l}2.4(-1.4,6.2) \\
p=0.2\end{array}$ & $\begin{array}{l}1.8(-2.0,5.7) \\
\mathrm{p}=0.3\end{array}$ & 0.9 \\
\hline$\Delta$ Heart rate & $\begin{array}{l}2.5(-0.8,5.9) \\
p=0.14\end{array}$ & $\begin{array}{l}3.3(0.1,6.4) \\
p=0.04\end{array}$ & $\begin{array}{l}3.6(0.3,6.8) \\
p=0.03\end{array}$ & $\begin{array}{l}3.1(-0.8,6.2) \\
p=0.056\end{array}$ & 0.3 \\
\hline$\Delta$ Pulse pressure & $\begin{array}{l}5.7(1.5,9.9) \\
\mathrm{p}=0.008\end{array}$ & $\begin{array}{l}5.9(1.8,9.9) \\
\mathrm{p}=0.004\end{array}$ & $\begin{array}{l}5.8(1.7,10.0) \\
\mathrm{p}=0.006\end{array}$ & $\begin{array}{l}5.5(1.0,10.0) \\
\mathrm{p}=0.018\end{array}$ & 0.5 \\
\hline
\end{tabular}

Regression coefficients represent the adjusted average difference in stress reactivity between those with an eGFR of $<60 \mathrm{ml} /$ $\mathrm{min} / 1.73 \mathrm{~m}^{2}$ or $\geq 60 \mathrm{ml} / \mathrm{min} / 1.73 \mathrm{~m}^{2}$. Stress reactivity measures were computed for all 3 stressors.

Model 1: adjusted for age, gender, race, body mass index $\left(\mathrm{kg} / \mathrm{m}^{2}\right)$, aspirin use, and hypertension.

Model 2: additionally adjusted for fasting glucose and plasma glucose $120 \mathrm{~min}$ following an oral glucose load.

Model 3: Adjusted for covariates in model 1 and additionally for HDL-C, triglycerides, and LDL-C. 
Table 3. Association between eGFR and stress reactivity measures

\begin{tabular}{|c|c|c|c|c|c|}
\hline \multirow{2}{*}{$\begin{array}{l}\text { Hemodynamic } \\
\text { measure }\end{array}$} & \multicolumn{4}{|c|}{ Regression coefficient (95\% CI) } & \multirow{2}{*}{$\begin{array}{l}\text { Test for task- } \\
\text { GFR interaction }\end{array}$} \\
\hline & unadjusted & model 1 & model 2 & model 3 & \\
\hline$\Delta \mathrm{SBP}$ & $1.32(0.29,2.36)$ & $0.99(-0.09,2.08)$ & $1.35(0.29,2.41)$ & $0.85(-0.20,1.90)$ & 0.7 \\
\hline$\Delta \mathrm{DBP}$ & $0.70(0.11,1.28)$ & $0.47(-0.12,1.07)$ & $0.68(0.11,1.25)$ & $0.44(-0.16,1.03)$ & 0.8 \\
\hline$\Delta$ Heart rate & $0.17(-0.37,0.72)$ & $0.06(-0.50,0.61)$ & $0.25(-0.29,0.79)$ & $-0.03(-0.59,0.52)$ & 0.4 \\
\hline$\Delta$ Pulse pressure & $0.71(-0.02,1.45)$ & $0.58(-0.19,1.36)$ & $0.74(-0.04,1.52)$ & $0.47(-0.27,1.20)$ & 0.7 \\
\hline
\end{tabular}

Regression coefficients represent the difference in mean stress response associated with a $10 \mathrm{ml} / \mathrm{min}$ lower eGFR, holding other factors constant. Stress reactivity measures were computed for all 3 stressors combined.

Model 1: Adjusted for age, gender, race, sex, body mass index $\left(\mathrm{kg} / \mathrm{m}^{2}\right)$, aspirin use, and hypertension.

Model 2: Additionally adjusted for fasting glucose and plasma glucose $120 \mathrm{~min}$ following oral glucose load.

Model 3: Adjusted for covariates in model 1 and additionally for HDL-C, triglycerides, and LDL-C.

did not materially change the results (model 2). Adjustment for fasting lipid profile (LDL-C, HDL-C, and triglycerides) resulted in a modest attenuation of the estimated regression coefficients (table 2; model 3). Associations of low eGFR and stress reactivity did not differ significantly across experimental tasks ( $\mathrm{p}>0.3$ for tests of interaction).

When eGFR was considered as a continuous predictor variable, a significant linear relationship with SBP and DBP reactivity was noted in unadjusted models (table 3 ). However, after adjustment for age, gender, race, body mass index, hypertension, and aspirin use, the associations were attenuated and no longer significant (table 3; model 1). After further adjustment for fasting glucose and post-challenge glucose levels (model 2), there were significant albeit moderate linear associations of eGFR and SBP and DBP reactivity. In contrast, no linear associations were observed after adjustment for lipid levels (model 3). No interaction between eGFR and experimental task was noted for any of the multivariate models.

\section{Discussion}

Among a cohort of older community-dwelling individuals free of clinical cardiac disease and stroke, individuals with lower eGFR had significantly greater hemodynamic responses to experimentally induced mental stress. This association was observed even after adjusting for prevalent hypertension, demographic factors, body mass index, aspirin use, and glycemic factors, and did not differ significantly across the three experimental mental tasks - anger recall, role play, and mental arithmetic. To our knowledge, this is the first study to demonstrate an association between impaired renal function and greater CVR. These results are especially notable in light of the relatively mild degree of renal impairment observed in the study cohort. It is possible that an even greater CVR to stress is present among individuals with more severe renal impairment.

Several decades of research have linked greater CVR to stress with the development of essential hypertension [1] and acute clinical stroke [2], and with a greater severity of subclinical vascular disease including coronary calcification [3], carotid intima-media thickness [4], inducible myocardial ischemia [20], and subclinical infarcts and white matter disease in the brain [5]. Hemodynamic responses to mental and emotional stress induced in an experimental laboratory setting have been shown to correlate with responses exhibited during normal daily activities [6], and it is possible that such reactivity occurring repeatedly and chronically can lead to the development of vascular injury. Patients with impaired renal function are at much greater risk for cardiovascular disease and morbidity, including stroke [21], subclinical brain infarct [22], carotid artery intima-media hyperplasia [23], and coronary calcification [24] - results of the present study raise the possibility that exaggerated responses to stress could explain in part this increased vascular risk.

The association we observed between impaired renal function and cardiovascular stress reactivity may be explained by a number of causal and/or mediating factors. Individuals with CKD exhibit baseline hyperactivity of the sympathetic nervous system $[8,9]$, which may play a direct role in mediating CVR to emotional stress. A deficiency in nitric oxide availability [25] and impairment 
of endothelial function $[26,27]$ are also common in CKD and could plausibly explain the relation with CVR. Alternatively, individuals who exhibit exaggerated responses to experimentally induced stress may have suffered direct renal injury as a result of this increased reactivity. In support of this hypothesis, Schmieder et al. [28] reported that subjects with mild hypertension experienced increased circulating angiotensin II along with decreased renal blood flow, glomerular hypertension, and increased systemic blood pressure in response to experimentally induced mental stress; these hemodynamic glomerular changes might be expected to contribute to permanent renal injury if sustained or repeated over the long term.

It is also plausible that metabolic factors such as dyslipidemia and insulin resistance, which are highly prevalent in CKD, could explain or mediate some of the effects of renal function on stress reactivity $[29,30]$; our results suggest that high triglycerides and low HDL-C account for at least some of the correlation between renal function and CVR. However, the causal direction of these correlations cannot be determined in this cross-sectional study.

Whether the relationship between renal function and cardiovascular stress reactivity is linear or exhibits a threshold effect is somewhat unclear. A priori we chose a cutoff point of $60 \mathrm{ml} / \mathrm{min} / 1.73 \mathrm{~m}^{2}$ to classify eGFR as impaired or non-impaired, based on the standard definition of stage III or greater CKD according to the National Kidney Foundation criteria [18]; this cutoff point identifies those with a higher risk of cardiovascular outcomes and death [12]. Post-hoc examination of multiple different cutoff points was avoided due to the high likelihood of a type I error. Although no significant linear relationship was observed between eGFR and stress reactivity measures in the primary regression model, there were modest but significant linear associations observed after additional adjustment for glycemic status.

The strengths of this study include the well-characterized study population that was largely free of diabetes and overt cardiovascular disease, thus eliminating these important influences as potential confounders. Limitations include the use of formula-derived estimates of GFR rather than direct isotope-based measures. Although the estimating equation of Levey et al. [14] is clearly superior to that of unadjusted creatinine in predicting true GFR, there is still considerable error in the estimate, especially when the true GFR is in the normal range (i.e., $>90 \mathrm{ml} /$ $\min / 1.73 \mathrm{~m}^{2}$ ) [31]. However, one would expect this error to be random with regard to stress reactivity measures; the effect of this non-differential error is to bias the estimated regression coefficients towards zero (no association of eGFR and stress reactivity), so that the true associations may be even greater than those estimated in our analysis. The small number of individuals with impaired estimated renal function in this study population limits the statistical power of the analysis and precludes exploration of effect modification by other factors. Although those participants (15\%) who were on antihypertensive treatment were tested after 2 weeks of supervised medication withdrawal, we cannot exclude the possibility of residual medication effects, especially among those with low GFR in whom the half-life of long-acting renally excreted drugs may be prolonged. However, this residual medication effect would be expected to attenuate CVR to a greater extent among those with low GFR, whereas we observed a greater CVR among this group. As nearly $50 \%$ of the participants were active smokers and were not required to refrain from smoking prior to reactivity testing, we cannot exclude an acute effect of recent tobacco use on the observed stress responses. However, the proportion of smokers was similar among those with and without low GFR, so major confounding by smoking is unlikely. Additionally, no measures of albuminuria or proteinuria were collected as part of this study; it is possible that these measures, which often reflect early renal injury, may also predict greater cardiovascular responses to stress and therefore confound the relationship between GFR and stress reactivity.

In conclusion, we have demonstrated for the first time that older individuals with mild-moderate renal impairment have a greater cardiovascular response to mental stress, a putative vascular risk factor. In light of the small sample of individuals with low GFR, these results should be confirmed in a larger study population. Further investigation is also warranted into the factors that mediate this relationship and the clinical consequences of this exaggerated response to stress in individuals with CKD.

\section{Acknowledgements}

This work was supported by the National Institute on Aging R29 AG15112, RO1 AG15112; the Department of Veteran Affairs Geriatric Research, Education and Clinical Center Grant (GRECC), a VA Merit Grant, and the University of Maryland Claude D. Pepper Older Americans Independence Center (P60AG12583). S.L.S. is supported by a grant from the National Institute of Diabetes, Digestive, and Kidney Disease (K23-63079). 


\section{References}

1 Matthews KA, Katholi CR, McCreath H, Whooley MA, Williams DR, Zhu S, Markovitz JH: Blood pressure reactivity to psychological stress predicts hypertension in the CARDIA study. Circulation 2004;110:7478.

-2 Everson SA, Lynch JW, Kaplan GA, Lakka TA, Sivenius J, Salonen JT, Matthews KA: Stress-induced blood pressure reactivity and incident stroke in middle-aged men. Stroke 2001;32:1263-1270.

>3 Matthews KA, Zhu S, Tucker DC, Whooley MA: Blood pressure reactivity to psychological stress and coronary calcification in the Coronary Artery Risk Development in Young Adults Study. Hypertension 2006;47: 391-395.

4 Matthews KA, Owens JF, Kuller LH, SuttonTyrrell K, Lassila HC, Wolfson SK: Stress-induced pulse pressure change predicts women's carotid atherosclerosis. Stroke 1998;29: 1525-1530.

5 Waldstein SR, Siegel EL, Lefkowitz D, Maier KJ, Brown JR, Obuchowski AM, Katzel LI: Stress-induced blood pressure reactivity and silent cerebrovascular disease. Stroke 2004; 35:1294-1298.

6 Kamarck TW, Schwartz JE, Janicki DL, Shiffman S, Raynor DA: Correspondence between laboratory and ambulatory measures of cardiovascular reactivity: a multilevel modeling approach. Psychophysiology 2003;40:675-683.

7 Manuck SB, Kasprowicz AL, Muldoon MF: Behaviorally-evoked cardiovascular reactivity and hypertension: conceptual issues and potential associations. Ann Behav Med 1990; 12:17.

$>_{8}$ Neumann J, Ligtenberg G, Klein II, Koomans HA, Blankestijn PJ: Sympathetic hyperactivity in chronic kidney disease: pathogenesis, clinical relevance, and treatment. Kidney Int 2004;65:1568-1576.

$\checkmark 9$ Koomans HA, Blankestijn PJ, Joles JA: Sympathetic hyperactivity in chronic renal failure: a wake-up call. J Am Soc Nephrol 2004; 15:524-537.

10 Wannamethee SG, Shaper AG, Perry IJ: Serum creatinine concentration and risk of cardiovascular disease: a possible marker for increased risk of stroke. Stroke 1997;28:557563.
11 Fried LF, Shlipak MG, Crump C, Bleyer AJ, Gottdiener JS, Kronmal RA, Kuller LH, Newman AB: Renal insufficiency as a predictor of cardiovascular outcomes and mortality in elderly individuals. J Am Coll Cardiol 2003;41:1364-1372.

12 Go AS, Chertow GM, Fan D, McCulloch CE, Hsu CY: Chronic kidney disease and the risks of death, cardiovascular events, and hospitalization. N Engl J Med 2004;351: 1296-1305.

13 Waldstein SR, Katzel LI: Stress-induced blood pressure reactivity and cognitive function. Neurology 2005;64:1746-1749.

14 Levey AS, Greene T, Kusek J, Beck G: A simplified equation to predict glomerular filtration rate from serum creatinine (abstract). J Am Soc Nephrol 2000;11:A0828.

15 Expert Committee on the Diagnosis and Classification of Diabetes: Diagnosis and Classification of Diabetes Mellitus. Diabetes Care 2004;27:5S-10S.

16 Ironson G, Taylor CB, Boltwood M, Bartzokis T, Dennis C, Chesney M, Spitzer S, Segall GM: Effects of anger on left ventricular ejection fraction in coronary artery disease. Am J Cardiol 1992;70:281-285.

17 Waldstein SR, Burns HO, Toth MJ, Poehlman ET: Cardiovascular reactivity and central adiposity in older African Americans. Health Psychol 1999;18:221-228.

18 National Kidney Foundation: K/DOQI Clinical Practice Guidelines for Chronic Kidney Disease: Evaluation, Classification, and Stratification. Am J Kidney Dis 2002;39 (suppl 1):S17-S31.

19 Kamarck TW, Jennings JR, Debski TT, Glickman-Weiss E, Johnson PS, Eddy MJ, Manuck SB: Reliable measures of behaviorally-evoked cardiovascular reactivity from a PC-based test battery: results from student and community samples. Psychophysiology 1992;29:17-28.

20 Kral BG, Becker LC, Blumenthal RS, Aversano T, Fleisher LA, Yook RM, Becker DM: Exaggerated reactivity to mental stress is associated with exercise-induced myocardial ischemia in an asymptomatic high-risk population. Circulation 1997;96:4246-4253.

21 Manolio TA, Kronmal RA, Burke GL, O'Leary DH, Price TR: Short-term predictors of incident stroke in older adults. The Cardiovascular Health Study. Stroke 1996; 27:1479-1486.
22 Seliger SL, Longstreth WT Jr, Katz R, Manolio T, Fried LF, Shlipak M, Stehman-Breen CO, Newman A, Sarnak M, Gillen DL, Bleyer A, Siscovick DS: Cystatin C and subclinical brain infarction. J Am Soc Nephrol 2005; 16:3721-3727

23 Ishimura E, Shoji T, Emoto M, Motoyama K, Shinohara K, Matsumoto N, Taniwaki H, Inaba M, Nishizawa Y: Renal insufficiency accelerates atherosclerosis in patients with type 2 diabetes mellitus. Am J Kidney Dis 2001;38:S186-S190.

24 Fox CS, Larson MG, Keyes MJ, Levy D, Clouse ME, Culleton B, O’Donnell CJ: Kidney function is inversely associated with coronary artery calcification in men and women free of cardiovascular disease: the Framingham Heart Study. Kidney Int 2004; 66:2017-2021.

25 Schmidt RJ, Baylis C: Total nitric oxide production is low in patients with chronic renal disease. Kidney Int 2000;58:1261-1266.

26 Annuk M, Zilmer M, Lind L, Linde T, Fellstrom B: Oxidative stress and endothelial function in chronic renal failure. J Am Soc Nephrol 2001;12:2747-2752.

$\checkmark 27$ Perticone F, Maio R, Tripepi G, Zoccali C: Endothelial dysfunction and mild renal insufficiency in essential hypertension. Circulation 2004;110:821-825.

28 Schmieder RE, Veelken R, Schobel H, Dominiak P, Mann JF, Luft FC: Glomerular hyperfiltration during sympathetic nervous system activation in early essential hypertension. J Am Soc Nephrol 1997;8:893-900.

$>29$ Burker EJ, Fredrikson M, Rifai N, Siegel W, Blumenthal JA: Serum lipids, neuroendocrine, and cardiovascular responses to stress in men and women with mild hypertension. Behav Med 1994;19:155-161.

30 Waldstein SR, Burns HO: Interactive relation of insulin and gender to cardiovascular reactivity in healthy young adults. Ann Behav Med 2003;25:163-171.

31 Bostom AG, Kronenberg F, Ritz E: Predictive performance of renal function equations for patients with chronic kidney disease and normal serum creatinine levels. J Am Soc Nephrol 2002;13:2140-2144. 